\title{
Near-Infrared Visual Differentiation in Normal and Abnormal Breast Using Hemoglobin Concentrations
}

\author{
Parinaz Mehnati ${ }^{1}$, Sirous Khorram², Mohammad Sadegh Zakerhamidi ${ }^{2}$, Farhood Fahima ${ }^{3 *}$ \\ ${ }^{1}$ Department of Medical Physics, School of Medicine, Tabriz University of Medical Sciences, Tabriz, Iran \\ ${ }^{2}$ Research Institute for Applied Physics and Astronomy, Tabriz University, Tabriz, Iran \\ ${ }^{3}$ Student Research Committee, Tabriz University of Medical Sciences, Tabriz, Iran
}

\author{
*Correspondence to \\ Farhood Fahima, Student \\ Research Committee, Tabriz \\ University of Medical Sciences, \\ Tabriz, Iran. \\ Tel, Fax: +984133364660 \\ Mobile: +98 9143062123; \\ Email: \\ Farhood_Fahima@yahoo.com
}

Published online 26 December 2017

\begin{abstract}
Introduction: Near-infrared (NIR) optical imaging is a non-ionizing modality that is emerging as a diagnostic/prognostic tool for breast cancer according to NIR differentiation of hemoglobin $(\mathrm{Hb})$ concentration.

Methods: The transmission values of LED-sourced light at $625 \mathrm{~nm}$ were measured by power meter to evaluate the optical properties of $\mathrm{Hb}$ in breast phantom containing major and minor vessels. For the simulation of blood variations in cancerous breast condition, we prepared 2 concentrations of pre-menopausal $\mathrm{Hb}$ and 4 concentrations of post-menopausal $\mathrm{Hb}$ and, for comparison with normal tissue, one concentration of $\mathrm{Hb}$ injected inside the phantom's vessels. Imaging procedure on the phantom was also conducted by LED source and CCD camera. The images from the experiments were compared with the results obtained from the images analyzed by MATLAB software. Finally, mammography of phantom including various concentration of $\mathrm{Hb}$ was prepared.

Results: The transmitting intensities of NIR in blood containing 1,2 and 4 concentrations of $\mathrm{Hb}$ in the major vessels were $52.83 \pm 2.85,43.00 \pm 3.11$ and $31.17 \pm 2.27 \mu \mathrm{W}$, respectively, and in minor vessels containing similar $\mathrm{Hb}$ concentrations were $73.50 \pm 2.43,60.08 \pm 5.09$ and $42.42 \pm 4.86 \mu \mathrm{W}$, respectively. The gray-scale levels on the major vessel were about 96, 124, 162 and on the minor vessel about 72, 100, 130 measured for 1,2 and $4 \mathrm{Hb}$ concentrations, respectively. The sensitivity and specificity of NIR imaging differentiation were $97.4 \%$ and $91.3 \%$, respectively.

Conclusion: Significant differences in transmitting intensity, optical imaging as well as software analysis of images were observed for 1,2 and 4 concentrations of $\mathrm{Hb}$ in major and minor breast phantom vessels. Differentiation capability of minor vessels was higher than major vessels for $\mathrm{Hb}$ concentrations. Despite a good detection for location of vessels by mammography, it could not show differences between vessels with various concentrations. However, NIR optical imaging demonstrated a good image contrast for showing vessels in terms of concentration. This study recommends NIR optical imaging for prescreening breast cancer due to its potential for early diagnosis.

Keywords: Hemoglobin concentrations; Imaging; Near-infrared; Optical properties.
\end{abstract}

\section{Introduction}

Breast cancer is the most common type of cancer among women and the second leading cause of cancer death in women worldwide. ${ }^{1}$ The prevalence of breast cancer deaths is about $60 \%$ in economically developing countries. $^{2}$ Early diagnosis of breast cancer is an important issue among researchers, helping treatment in up to $95 \%$ of the cases ${ }^{3}$ by inhibiting metastatic cells prior to spreading to other regions. For this reason, modalities for accurate and early diagnosis may ensure better prognosis, resulting in higher survival rates. Even though various breast cancer screening methods, such as magnetic resonance imaging (MRI), ultrasound (US), breast computed tomography (bCT) and mammography, are in general use in clinics, each of such modalities has its own disadvantages. MRI has limited specificity, long time of image acquisition and high cost of examination; US has low sensitivity in monitoring for small nodules; bCT also has high examination cost and accompanies risks of radiation exposure for the patients; and mammography uses ionizing radiation, and has limited specificity for radiodense breasts. ${ }^{4,5}$ In addition, high density breast tissues are in higher risks of cancer and require a shorter period of examination ${ }^{6,7}$; nevertheless, mammography is not recommended for women under 40 years old due to the accompanying radiation-related damage. ${ }^{8}$

Over the past 3 decades, optical imaging techniques have been introduced as a functional imaging modality using non-invasive light in near-infrared (NIR) spectral region, ${ }^{2,3}$ with the early diagnostic ability to detect the first signs of the forming up of breast cancer. ${ }^{9}$ Unlike other modalities mentioned above, optical mammography technique is

Please cite this article as follows: Mehnati P, Khorram S, Zakerhamidi MS, Fahima F. Near-infrared visual differentiation in normal and abnormal breast using hemoglobin concentrations. J Lasers Med Sci. 2018;9(1):50-57. doi:10.15171/jlms.2018.11. 
non-ionizing, cost-effective and safe to repeat. Light at the NIR optical region (600-1000 nm) has energy levels between 2.06 and $1.23 \mathrm{eV} /$ photon which is much lower than what needed to induce a biological damage such as DNA fragmentation, and cell apoptosis. ${ }^{10,11}$

This technique is potentially one of the harmless screening methods for women who do not show the initial symptoms of breast cancer. ${ }^{2}$ Optical imaging technique is based on the detection of light after its interaction (including absorption and scattering) with tissue. ${ }^{12}$ Light distribution in a biological tissue depends on the optical properties of the tissue. ${ }^{13}$ As the tissue consists of various chromophores, such as oxyhemoglobin and deoxyhemoglobin, myoglobin, cytochromes, melanin, and water, different optical properties of these substances provide valuable information about the hemoglobin $(\mathrm{Hb})$ concentration, and lipid and water content in the NIR spectrum. ${ }^{14}$

The main disadvantages of optical imaging are that the depth of penetration is limited and lower spatial resolution as the energy of photons is low. Perhaps another disadvantage of this method is related to the operator ability for distinguishing normal and abnormal Hb points. ${ }^{15-17}$

Commonly, in tumoral tissue of breast cancer, abnormal proliferation of cells results in an increased number of blood vessels, eventually increasing local blood $\mathrm{Hb}$ concentration. In this regard, studies have shown that breast lesions contain a higher $\mathrm{Hb}$ concentration, approximately twice that of background tissues. ${ }^{7,18-20}$ Higher angiogenesis and cell hypermetabolism are characteristics of tumoral tissues of breast cancer, ${ }^{21}$ leading to higher $\mathrm{Hb}$ concentration and lower $\mathrm{Hb}$ saturation, respectively. ${ }^{22}$ Greater water and lower lipid contents in tumoral breast tissue compared to healthy tissue have been reported. ${ }^{18,23,24}$ Furthermore, the high $\mathrm{Hb}$ and water, and low fat concentrations in malignant lesions can make for diagnosis of malignant and benign lesions based on blood volume, and saturation or both. ${ }^{25-}$ ${ }^{27}$ Based on these facts, the existence of differences of $\mathrm{Hb}$ concentrations between tumoral and normal tissue could indicate tissue metabolic rate, which potentially provides better diagnosis and monitoring capabilities in optical mammography for breast cancer.

This study looks at the potential of optical mammography for imaging of different concentrations of $\mathrm{Hb}$, compared to $\mathrm{x}$-ray mammography. The goal here was measuring and imaging of NIR transmittance values of the phantom, including different concentrations of $\mathrm{Hb}$ and other breast components, including water and lipid.

\section{Methods}

Tissue Phantom and Samples

In this study, we used a polyethylene breast phantom designed and produced in our previous work and approved by Iran Intellectual Property Office (patent number: 85646). This phantom had ideal and similar optical properties to normal breast tissue. The phantom size was $185 \times 125 \mathrm{~mm}^{2}$ with a thickness of $50 \mathrm{~mm}$, which was simulated to a normal breast size. The phantom used for imaging process included 2 major and minor vessels with 10 and $5 \mathrm{~mm}$ diameters, respectively. In this experiment NIR transmission of $\mathrm{Hb}$ in major and minor types of vessels were measured at $15 \mathrm{~mm}$ depth according to the following formula (1)

$\mathrm{TIR}_{\text {NIR }} \%=\left[\left(\mathrm{TI}_{\text {without substance }}-\mathrm{TI}_{\text {with substance }}\right) / \mathrm{TI} \mathrm{w}_{\text {without substance }}\right] \times 100$

Where TI is the transmitting intensity of light. $\mathrm{TIR}_{\mathrm{NIR}} \%$ was calculated by measuring TI with and without substance in similar and fixed points on the phantom. $\mathrm{TIR}_{\mathrm{NIR}} \%$ indicates percentage of transmitted intensity of phantom with or without substance injected to blood vessels.

At the beginning of the experiment, phantom without substance was used for calculating the percentage of transmitting intensity ratio of NIR source $\left(\mathrm{TIR}_{\mathrm{NIR}} \%\right)$. According to formula 1 , decreases in $\mathrm{TI}_{\text {with substance }}$ result in increases in $\mathrm{TIR}_{\mathrm{NIR}} \%$. As shown in Figure 1, these points included 4 points on the major vessels and 4 other points on the minor vessels.

Healthy blood samples with $\mathrm{Hb}$ concentrations of 146 $\mathrm{g} / \mathrm{L}$ were obtained from the general hospital laboratory in Tabriz, Iran. Blood samples were centrifuged at 1500 $\mathrm{rpm}$ at room temperature for 10 minutes. Then, different concentrations of $\mathrm{Hb}(1,2$, and 4-fold) were prepared by diluting the blood samples with phosphate-buffered saline (PBS). Water and lipid (as the main breast components) and also $1 \times, 2 \times$ or $4 \times$ concentrations of $\mathrm{Hb}$ were used as a contrast agent. About 6 and $3.5 \mathrm{~mL}$ of each substance was injected into major and minor vessels of the phantom, respectively.

Instrumentation and Optical Imaging Procedure

Previous experiments showed good separation for different concentrations of $\mathrm{Hb}$ at $620-640 \mathrm{~nm}$ wavelengths. ${ }^{28}$ Based on this result, the NIR from LEDs source at $625 \pm 5 \mathrm{~nm}$ wavelengths on continuous wave mode was used as a light source. The device included 54 diodes with an output

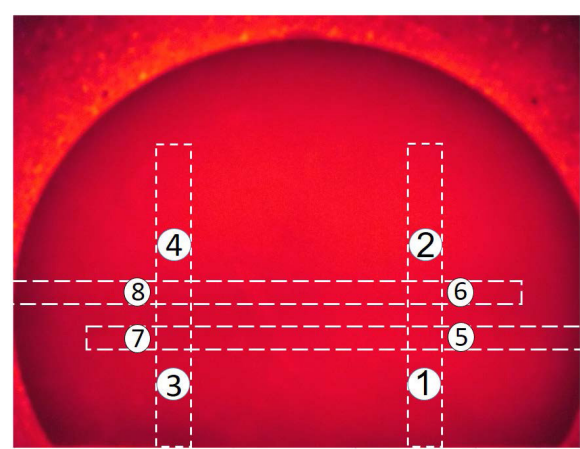

Figure 1. Breast Phantom Without Substance. Four different points (number 1-4) on the major vessels and 4 other points (number 5-8) on the minor vessels were considered. 
power of $100 \mathrm{~mW}$, equipped with a controller box in order to regulate output power. The NIR LEDs light transmitted values were measured by an optical power meter (model PM100D, ThorLabs GmbH, Dachau, Germany) with an aperture size of $9.5 \mathrm{~mm}$ and $1 \mathrm{nW}$ precision. A digital NIR-sensitive Charge Coupled Device (CCD) camera (Casio EXILIM EX-Z35, Japan) was used for optical imaging. This highly sensitive NIR camera can produce high-resolution images of $\mathrm{Hb}$ concentrations in the breast phantom. NIR source was located at the bottom of the phantom. For the measurement of TI, the power meter was placed on the phantom. For imaging procedures, CCD camera was placed $160 \mathrm{~mm}$ from the top of the phantom for optimal view. To avoid optical disturbances, imaging procedures were carried out in a dark box at room temperature. Different concentrations of $\mathrm{Hb}$, water and lipid were selected to record the transmission values of NIR from breast phantom vessels.

\section{Mammography of Phantom}

Mammography is the common method for breast cancer screening. In this study, mammograms of breast phantom were taken for comparisons with NIR-images. The mammography for this study used an automatic conventional $x$-ray equipment (model PMA, 100-F) with $36 \mathrm{mAs}$ and $22 \mathrm{kV}$, with source skin distance (SSD) at 60 $\mathrm{cm}$, manufactured by Payamed, Tehran, Iran. The major and minor vessels of the phantom were filled out by different concentrations of $\mathrm{Hb}(1 \times, 2 \times$ or $4 \times)$ and images were performed on the $18 \mathrm{~cm} \times 24 \mathrm{~cm}$ film.

\section{Image Processing}

Image processing was carried out using a MATLAB (R2010a, The Mathworks, Natick, Massachusetts, USA) software. The first step was to co-register the raw NIR images, so that the 2 images were aligned on the same coordinate system. This was followed by subtraction of the NIR image of the breast phantom obtained without substance from the NIR image obtained with various concentrations of $\mathrm{Hb}$ present. The regions outside the breast phantom were masked (or cropped) in order to improve the image contrast by removing the noise. Finally, minimum and maximum pixel values were set by the user in order to distinguish areas of increased or decreased absorption in the image, allowing for the recognition of the target with improved contrast. The targets were seen as areas with increased absorption.

\section{Data Analysis}

The data were analyzed using the SPSS statistics software version 16.0. Comparisons of different groups for TI were carried out by a one-way analysis of variance (ANOVA) followed by the post hoc Tukey test. All data are expressed as means \pm standard deviation (SD). $P<0.05$ was considered statistically significant.

\section{Results}

NIR Transmitting Ratio for Major Vessels

TI values of the phantom without substance in point 1 to 4 on the major vessels located at $15 \mathrm{~mm}$ depths and measured by power meter were $93.67 \pm 1.70,94.33 \pm 2.62$, $92.00 \pm 4.32$, and $93.00 \pm 2.16 \mu \mathrm{W}$, respectively. After the injection of different concentrations of $\mathrm{Hb}$, water and lipid in major vessels of the phantom, TI was determined. There was a significant difference between $1 \times \mathrm{Hb}$ concentration and water and lipid $(P<0.001)$ for TI values. There was no significant difference in TI of water, lipid and phantom without substance $(P>0.05)$. TI values for $1 \times, 2 \times$ or $4 \times$ $\mathrm{Hb}$ decreased with $\mathrm{Hb}$ concentration increasing, while $\mathrm{TIR}_{\mathrm{NIR}} \%$ increased. There was a significant difference between $2 \times \mathrm{Hb}(P<0.05)$ and $4 \times \mathrm{Hb}(P<0.001)$ when compared with $1 \times \mathrm{Hb}$ for TI values. The percentage of TIR was calculated according to formula 1 as shown in Table 1.

NIR Transmitting Ratio for Minor Vessels

The TI values in point 5 to 8 on the minor vessels, located at $15 \mathrm{~mm}$ depth, were $95.00 \pm 2.04,91.25 \pm 1.76$, $92.08 \pm 2.56$, and $93.75 \pm 3.67 \mu \mathrm{W}$, respectively. After the injection of different concentrations of $\mathrm{Hb}$ and water into minor vessels of the phantom, the $\mathrm{TI}$ and $\mathrm{TIR}_{\mathrm{NIR}} \%$ values were measured as shown in Table 2 . There was a significant difference between $1 \times$, and $2 \times(P<0.05)$ and $4 \times(P<0.001) \mathrm{Hb}$ TI values. Also, transmittance measured for major and minor vessels at the $35 \mathrm{~mm}$ depth data was not shown.

Table 1. The Percentage of $\mathrm{TIR}_{\mathrm{NIR}}$ and TI of Breast Phantom Containing Water, Lipid, $1 \times, 2 \times$, and $4 \times$ Concentrations of Hb in Major Vessels by Power Meter $^{\mathrm{a}}$

\begin{tabular}{|c|c|c|c|c|c|c|}
\hline \multirow{2}{*}{ Substances } & \multicolumn{5}{|c|}{$\operatorname{TIR}_{\mathrm{NIR}} \%$} & \multirow{2}{*}{ Average (TI) } \\
\hline & Point 1 & Point 2 & Point 3 & Point 4 & Average & \\
\hline Water & $3.20 \pm 3.81$ & $4.24 \pm 5.44$ & $2.90 \pm 4.49$ & $3.23 \pm 4.68$ & $3.50 \pm 4.67$ & $96.42 \pm 3.07$ \\
\hline Lipid & $7.12 \pm 3.14$ & $5.65 \pm 3.20$ & $6.88 \pm 5.42$ & $7.53 \pm 3.05$ & $6.71 \pm 3.90$ & $86.92 \pm 2.87$ \\
\hline $1 \times \mathrm{Hb}$ & $43.42 \pm 2.10$ & $41.70 \pm 4.67$ & $44.57 \pm 3.44$ & $43.73 \pm 3.54$ & $43.27 \pm 3.71$ & $52.83 \pm 2.85$ \\
\hline $2 \times \mathrm{Hb}$ & $53.74 \pm 3.07$ & $52.65 \pm 4.03$ & $54.71 \pm 2.54$ & $54.48 \pm 2.83$ & $53.87 \pm 3.28$ & $43.00 \pm 3.11$ \\
\hline $4 \times \mathrm{Hb}$ & $66.90 \pm 0.61$ & $65.37 \pm 2.16$ & $67.03 \pm 2.09$ & $67.03 \pm 1.48$ & $66.60 \pm 1.85$ & $31.17 \pm 2.27$ \\
\hline
\end{tabular}

Abbreviations: TIR, transmitting intensity ratio; TI, transmitting intensity; $\mathrm{Hb}$, hemoglobin.

${ }^{a}$ Data are shown as mean \pm SD. 
Table 2. The Percentage of $\mathrm{TIR}_{\mathrm{NIR}}$ and TI of Breast Phantom Containing Water, Lipid, $1 \times, 2 \times$, and $4 \times$ Concentrations of Hb in Minor Vessels by Power Meter $^{\mathrm{a}}$

\begin{tabular}{|c|c|c|c|c|c|c|}
\hline \multirow{2}{*}{ Substances } & \multicolumn{5}{|c|}{$\mathrm{TIR}_{\mathrm{NIR}} \%$} & \multirow{2}{*}{ Average ( $\mathrm{TI})$} \\
\hline & Point 1 & Point 2 & Point 3 & Point 4 & Average & \\
\hline Water & $2.18 \pm 1.58$ & $1.23 \pm 1.72$ & $4.47 \pm 1.14$ & $3.99 \pm 1.87$ & $1.59 \pm 3.25$ & $94.49 \pm 4.09$ \\
\hline Lipid & $1.33 \pm 20.35$ & $0.51 \pm 19.63$ & $4.05 \pm 22.17$ & $2.13 \pm 21.78$ & $20.94 \pm 2.59$ & $73.50 \pm 2.43$ \\
\hline $1 \times \mathrm{Hb}$ & $34.74 \pm 4.85$ & $34.98 \pm 6.12$ & $35.57 \pm 4.41$ & $36.36 \pm 1.33$ & $35.44 \pm 4.57$ & $60.08 \pm 5.09$ \\
\hline $2 \times \mathrm{Hb}$ & $54.04 \pm 3.48$ & $55.43 \pm 5.60$ & $54.03 \pm 2.99$ & $54.13 \pm 6.34$ & $54.43 \pm 4.86$ & $42.42 \pm 4.86$ \\
\hline $4 \times \mathrm{Hb}$ & $66.90 \pm 0.61$ & $65.37 \pm 2.16$ & $67.03 \pm 2.09$ & $67.03 \pm 1.48$ & $66.60 \pm 1.85$ & $31.17 \pm 2.27$ \\
\hline
\end{tabular}

Abbreviations: TIR, transmitting intensity ratio; TI, transmitting intensity; $\mathrm{Hb}$, hemoglobin.

a Data are shown as mean $\pm \mathrm{SD}$.

Furthermore, data from power meter measurements showed more absorption in the major vessels up to $48 \%$ compared to minor vessels for $2 \times \mathrm{Hb}$ concentration. However, more differentiation was observed from $1 \times \mathrm{Hb}$ concentration in the minor vessel up to $45 \%$ compared to major vessels. In addition, there was more absorption in the major vessels up to $23 \%$ compared to minor vessels for $4 \times \mathrm{Hb}$ concentration. However, more differentiation from $1 \times \mathrm{Hb}$ in the minor vessels up to $42 \%$ compared to major vessels was obtained.

\section{Phantom Imaging by NIR Source}

The image of breast phantom without substance by NIR is found in Figure 1. The position of major vessels was at 30 $\mathrm{mm}$ from the lateral edges left and right vertically, and the position of minor vessels was 30 and $40 \mathrm{~mm}$ from bottom of the phantom horizontally. Images of both major and minor vessels at depths of $15 \mathrm{~mm}$ from the surface of the phantom were performed.

\section{Imaging of Phantom for Major Vessels}

For optical imaging of the phantom by LEDs source, water and lipid were injected into the left and right major vessels of the phantom, respectively. Significant differences between lipid, water and breast phantom were not observed $(P>0.05)$. Figure $2 \mathrm{~A}$ shows the phantom image when left and right major vessels were filled by $1 \times$ and $2 \times$ $\mathrm{Hb}$, respectively. According to the image contrast, vessels were separable from the background of the phantom. The image obtained by $1 \times$ and $4 \times$ concentration of $\mathrm{Hb}$ showed a good vessel contrast as shown in Figure 2B. Similarly, the image obtained by $2 \times$ and $4 \times$ concentration of $\mathrm{Hb}$ showed an appropriate vessel contrast, Figure $2 \mathrm{C}$.

The optical imaging of breast phantom was analyzed by MATLAB software. The image processing for major vessels of breast phantom is shown in Figure 3A, 3B, 3C. The concentrations of $\mathrm{Hb}$ for $\mathrm{A}, \mathrm{B}, \mathrm{C}$ in Figure 3 were similar to those in Figure 2.

Imaging of Phantom for Minor Vessels

The image of 3 different concentrations of $\mathrm{Hb}(1 \times, 2 \times$ or $4 \times$ ) when injected to minor vessels of Phantom is shown in Figure 2D, 2E, 2F. The photo contract of $\mathrm{Hb}$
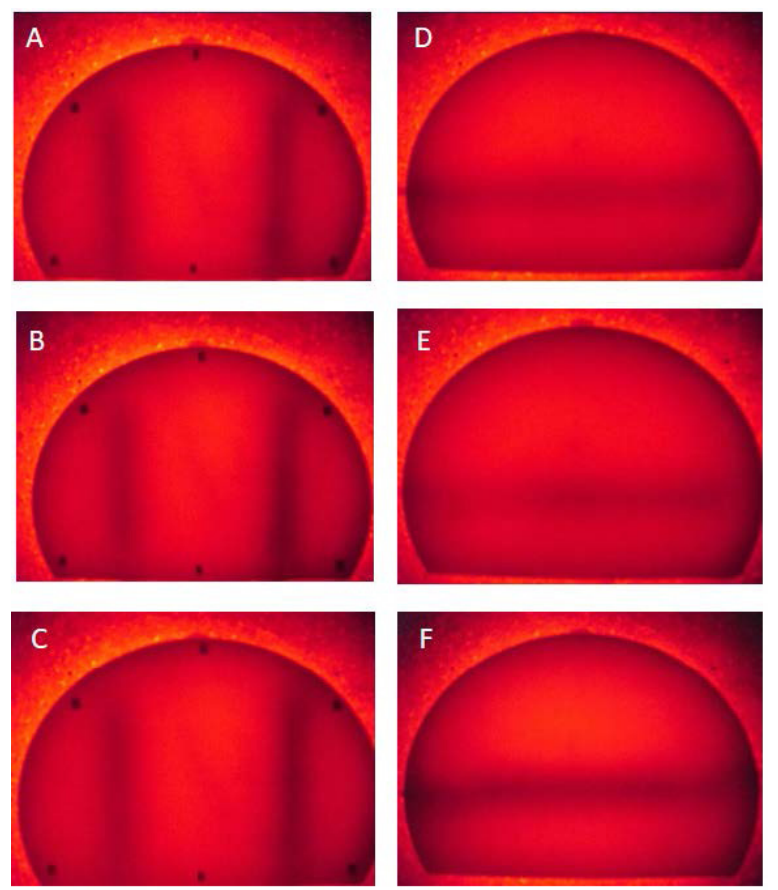

Figure 2. Imaging of Phantom for Major and Minor Vessels by NIR Source. (A) Image of phantom when left and right major vessels were filled by $1 \times$ and $2 \times$ concentration of $\mathrm{Hb}$; (B) $1 \times$ and $4 \times$ concentration of $\mathrm{Hb}$; (C) $2 \times$ and $4 \times$ concentration of $\mathrm{Hb}$; (D) Image of phantom when minor vessels were filled by $1 \times \mathrm{Hb}$; (E) $2 \times$ concentration of $\mathrm{Hb}$; (F): $4 \times$ concentration of $\mathrm{Hb}$.

concentration was studied by MATLAB software, and differences of the contrast between these substances for each concentration are shown in Figure 3D, 3E, 3F. This contrast for $1 \times \mathrm{Hb}$, Figure $3 \mathrm{D}$ and $2 \times \mathrm{Hb}$ Figure $3 \mathrm{E}$ and $4 \times \mathrm{Hb}$ Figure $3 \mathrm{~F}$ showed a good vessel contrast. To avoid thermal artifacts in optical Imaging, all experimental procedures were carried out at $24^{\circ} \mathrm{C}$.

\section{Quantitative Values of Image Processing}

On the image processing, which was done for NIR images, we quantified every pixel on the 8 points on the phantom for both major and minor vessels, as presented. In Figure 1 , the selected size of the points size was similar to the diameter of power meter aperture $(9.5 \mathrm{~mm})$. Then, the averages of gray-scale levels of the pixels for each point were calculated. It should be mentioned that the pixel 


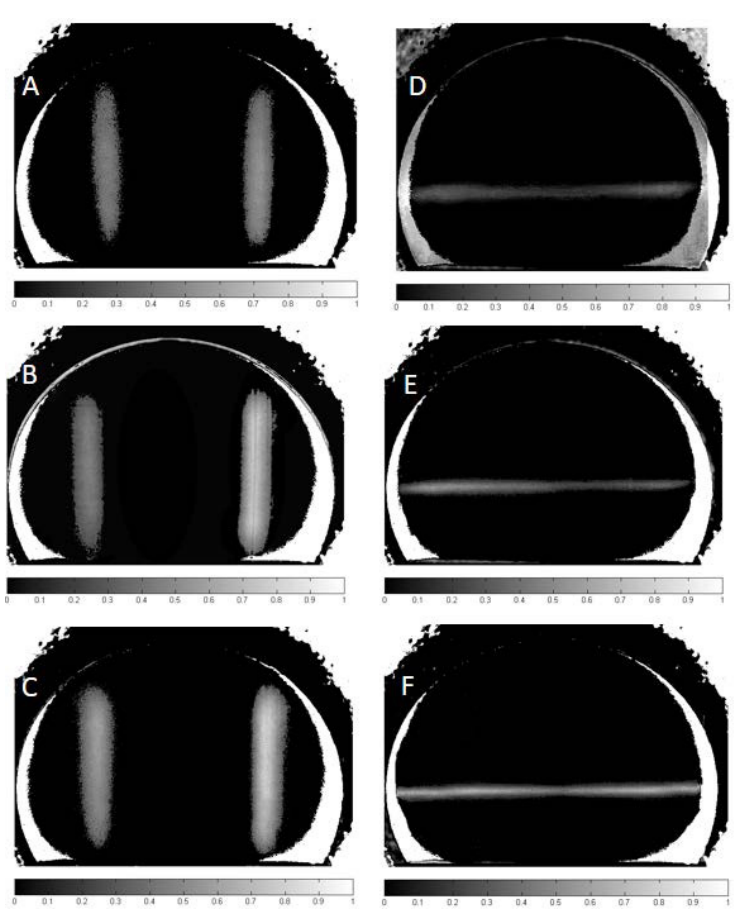

Figure 3. Processed Images of Phantom for Major and Minor Vessels. (A) Image of phantom when left and right major vessels were filled by $1 \times$ and $2 \times$ concentration of $\mathrm{Hb}$; (B) $1 \times$ and $4 \times$ concentration of $\mathrm{Hb}$; (C) $2 \times$ and $4 \times$ concentration of $\mathrm{Hb}$; (D) Image of phantom when minor vessels were filled by $1 \times \mathrm{Hb}$; (E) $2 \times$ concentration of $\mathrm{Hb}$; $(\mathrm{F})$ : $4 \times$ concentration of $\mathrm{Hb}$.

values of a gray-scale image ranged from 0 to 255 . The mean levels of each point of major and minor vessels for different concentrations of $\mathrm{Hb}$ showed significant differences (for all, $P<0.001$ ), as shown in Table 3 .

Our data from $\mathrm{TIR}_{\mathrm{NIR}} \%$ values after image processing showed more absorption in the major vessel up to $23 \%$ compared to minor vessels for $2 \times \mathrm{Hb}$ concentration. However, more differentiation from $1 \times \mathrm{Hb}$ concentration in the minor vessel up to $35 \%$ compared to major vessels was obtained. In addition, there was more absorption observed in the major vessel up to $24 \%$ compared to minor vessels for $4 \times \mathrm{Hb}$ concentration. However, more differentiation from $1 \times \mathrm{Hb}$ in the minor vessel up to $17 \%$ compared to major vessels was obtained.

\section{Mammography of Phantom}

As shown in Figure 4A, left and right major vessels of the phantom were injected by $1 \times$ and $2 \times \mathrm{Hb}$, respectively. Figure $4 \mathrm{~B}$ also shows left and right major vessels, when filled by $1 \times$ and $4 \times \mathrm{Hb}$, respectively. For the quantification

Table 3. The Mean Gray-Scale Levels of Major and Minor Vessels for Different Concentrations Hemoglobin

\begin{tabular}{lcc}
\hline Hb Concentration & Major & Minor \\
\hline $1 \times \mathrm{Hb}$ & $96.47 \pm 5.61$ & $72.82 \pm 7.97$ \\
$2 \times \mathrm{Hb}$ & $124.43 \pm 10.59$ & $100.94 \pm 13.78$ \\
$4 \times \mathrm{Hb}$ & $162.58 \pm 10.91$ & $130.28 \pm 10.20$ \\
\hline
\end{tabular}

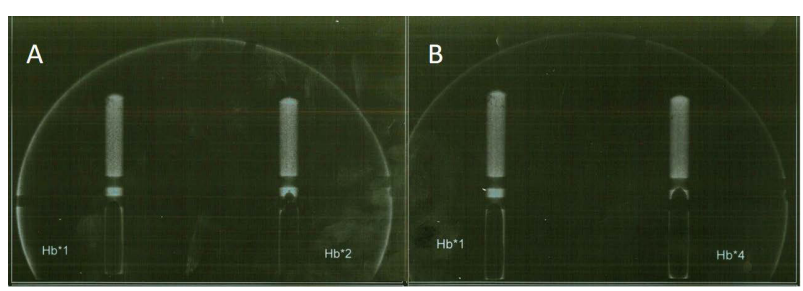

Figure 4. (A) Mammography of Phantom where $1 \times \mathrm{Hb}$ and $2 \times \mathrm{Hb}$ were injected in left and right major vessels of phantom; (B) Mammography of Phantom where $1 \times \mathrm{Hb}$ and $4 \times \mathrm{Hb}$ were injected in left and right major vessels of phantom.

of mammo images, a similar assay by NIR was performed on the mammogram. Subsequently, the averages of gray-scale levels of the pixels for each point were calculated. Contrary to data of NIR optical method in the mammography, the mean gray-scale levels of each point for various concentrations of $\mathrm{Hb}$ did not show significant differences (for all, $P>0.05$ ), as shown in Table 4.

\section{Discussion}

In this study, we found that using the polyethylene breast phantom within vessels to quantify NIR image of major and minor vessels filled by different $\mathrm{Hb}$ concentrations is an acceptable method for a reliable and proper NIR imaging process.

A positive correlation between power meter data and quantitative values of images is possible. It has been well established that tumoral tissues have elevated levels of $\mathrm{Hb}$ compared to normal tissue $\mathrm{e}^{18,29}$ and $\mathrm{Hb}$ concentrations are directly connected to the number of blood vessels, which is called angiogenesis and is a key factor necessary for tumor cells growth. ${ }^{30}$ Because $\mathrm{Hb}$ concentration is 2 and 4 times higher than normal in abnormal pre-menopausal and post-menopausal breast tissues, respectively. ${ }^{19,31,32}$ Leff et al in a systematic review showed that breast malignant patients with mean $\mathrm{Hb}$ concentration of $65 \pm 34 \mu \mathrm{mol} / \mathrm{L}$ approximately, carried at least twice the $\mathrm{Hb}$ concentration compared with normal breast $(\mathrm{Hb}=21 \pm 6 \mu \mathrm{mol} / \mathrm{L})$. Moreover, authors presented that the global mean $\mathrm{Hb}$ concentration in normal women is $34 \pm 9 \mu \mathrm{mol} / \mathrm{L}$ in premenopausal cases, and $14 \pm 0 \mu \mathrm{mol} / \mathrm{L}$ in post-menopausal women. ${ }^{19}$ This calculation showed a difference of 2 and 4 times of change of $\mathrm{Hb}$ between normal and abnormal cases, explaining the reasons for using the $1 \times \mathrm{Hb}$ as a normal tissue, $2 \times \mathrm{Hb}$ as abnormal pre-menopausal and $4 \times \mathrm{Hb}$ as abnormal post-menopausal breast tissues. This study, $\mathrm{Hb}$ concentration was termed for every age level. Data from breast phantom transmission showed that

Table 4. The Mean Gray-Scale Levels of Major and Minor Vessels for Different Concentrations Hemoglobin by Mammography

\begin{tabular}{lcc}
\hline Hb Concentration & Major & Minor \\
\hline $1 \times \mathrm{Hb}$ & $91.15 \pm 1.61$ & $42.12 \pm 2.13$ \\
$2 \times \mathrm{Hb}$ & $92.73 \pm 2.30$ & $43.04 \pm 1029$ \\
$4 \times \mathrm{Hb}$ & $93.52 \pm 3.25$ & $43.45 \pm 2.16$ \\
\hline
\end{tabular}


transmitting intensity (TI) values of $\mathrm{Hb}$ were significantly different from those in water and lipid. Furthermore, the $\mathrm{TIR}_{\mathrm{NIR}} \%$ values for $1 \mathrm{x}, 2 \times$ or $4 \times \mathrm{Hb}$ were in positive correlation with increases in $\mathrm{Hb}$ concentration. Another reason for validated results for water, lipid and $\mathrm{Hb}$ is their good potential for the separation of absorption coefficient of peak at NIR optical region. In the case of $\mathrm{Hb}$, high density of heme $(\mathrm{Fe})$ caused significant differentiation between various concentrations $(1 \times, 2 \times$ and $4 \times \mathrm{Hb}){ }^{14}$ In our results, heme differences were in $1 \times \mathrm{Hb}, 2 \times \mathrm{Hb}$, and $4 \times \mathrm{Hb}$. Also superficial vessels (in this study $15 \mathrm{~mm}$ ) could be differentiated better than deeper vessels ( $35 \mathrm{~mm}$ ) by NIR optical method.

NIR light at range of 625 to $1050 \mathrm{~nm}$ could be transmitted through several centimeters of breast tissue. The vessel chromophores of breast tissues act as a light absorber with maximum absorption in the mentioned wavelengths. ${ }^{8}$ In addition, the optical absorption coefficient of the cancerous region by more vessels, compared to adjacent normal areas, is showing different power meter values. Moreover, the various concentrations of $\mathrm{Hb}$ have a higher capability of detection of normal and abnormal breast tissue.

This study also showed that better differentiation was obtained for minor vessels for $1 \times \mathrm{Hb}$ and $2 \times \mathrm{Hb}$ concentrations as well as $1 \times \mathrm{Hb}$ and $4 \times \mathrm{Hb}$ compared to major vessels in both methods. Due to the closeness of optical properties of lipid and water to those in polyethylene, significant differences between these substances for TI values were not observable. In the current study, both types of vessels were located in 2 different depths, 15 and $35 \mathrm{~mm}$ from the phantom surface. In this experiment NIR transmitting of $\mathrm{Hb}$ in major and minor vessels were measured in the $15 \mathrm{~mm}$ depth and minor vessels were better detected (in terms of $\mathrm{Hb}$ concentration) in this depth. Transmittance measured for major and minor vessels at the $35 \mathrm{~mm}$ depth data was not shown; various detection experiments showed that a better differentiation between $\mathrm{Hb}$ concentrations was at a distance of $15 \mathrm{~mm}$ from the detector; therefore, it seems that an optimum image contrast could be accomplished by a minimum distance between vessels and the detector. These data are in good agreement with those reported by Ansari et $\mathrm{al}^{33}{ }^{33}$ which demonstrated depth of tissue as a key parameter in breast optical Imaging techniques for the detection of lesions. Previous studies showed a good separation at wavelengths of 620-640 nm for absorption characteristics of different concentrations of $\mathrm{Hb}$, which is in line with our present data. ${ }^{32}$ In this study, we used $625 \mathrm{~nm}$ for all test-measuring values of power meter and image processing. In another study, Taroni et al observed a contrast of tumoral tissue with lesion diameter of 1.5 $\mathrm{cm}$ observed in $637 \mathrm{~nm} .{ }^{28}$ Sensitivity values higher than about $90 \%$ and specificity values higher than $93 \%$ to distinguish between malignant and normal tissues in order to discriminate cancer from non-cancer tissues have been reported in different studies. ${ }^{19,34}$ Labib et al used a hand-held NIR (617 nm) optical mammogram in breast cancer prescreening of 310 women. Their findings for NIR breast cancer detection compared to X-ray mammography avidity obtained for $89.4 \%$ of cases matched to breast lesions that were identified by NIR optical device. Sensitivity of $93 \%$, and specificity of $73.7 \%$ were also reported by authors. ${ }^{35}$

In this study, image processing was conducted by a MATLAB-based software similar to that reported by Godavarty et al. ${ }^{2}$ For improving the detectability of images. In addition to MATLAB software, NIR images for major and minor vessels were processed by Image software too, and the result was similar (no significant difference was observed).

The analysis of optical imaging device's sensitivity and specificity (receiver operating characteristics [ROC]) was conducted to estimate the performance of the NIR images. The diagnosis of normal $(1 \times \mathrm{Hb})$ and abnormal breast vessels $(2 \times \mathrm{Hb}$ and $4 \times \mathrm{Hb}$ ) was $97.4 \%$ and $91.3 \%$, respectively. Therefore, NIR source $625 \mathrm{~nm}$ measurement turns out to be valid and reliable for separating normal and abnormal imaging of the breast by studying the phantom.

In summary, TI values after image processing showed more absorption in the major vessels compared to minor vessels for $2 \times \mathrm{Hb}$ and $4 \times \mathrm{Hb}$ concentration. However, more differentiation from $1 \times \mathrm{Hb}$ concentration in the minor vessels compared to major vessels was obtained. Also, data from power meter measurements showed similar results.

The comparison of images obtained by optical method and an x-ray mammography revealed that the quantified points of the phantom on the mammogram had similar levels of gray-scale for major and minor vessels. Our results showed that the image of breast with vessels phantom by mammography despite a good presenting of vessels locations, this technique has not acceptable ability for presenting differences between vessels with various concentrations $(1 \times \mathrm{Hb}$ versus $2 \times \mathrm{Hb}$, or $1 \times \mathrm{Hb}$ versus $4 \times \mathrm{Hb}$ ). However, NIR imaging technique demonstrated a good image contrast for showing vessels in terms of concentration.

As a result, optical imaging of breasts using NIR LEDs light could be potentially used as a non-invasive prescreening technique for examination of the breasts for early detection of cancer.

In conclusion, significant differences in TI, optical imaging as well as software analysis of images were observed for 1, 2 and 4 concentrations of $\mathrm{Hb}$ in major and minor breast phantom vessels. This study recommends NIR optical imaging for prescreening breast cancer due to its potential for early diagnosis.

\section{Conflict of Interests}

The authors declare that they have no conflict of interest. 


\section{Ethical Considerations}

This study approved by ethical committee of Tabriz University of medical science research (IR.TBZMED. REC.1395.116).

\section{Acknowledgments}

This work was supported by the office of the vice president for research in Tabriz University of Medical Sciences, Iran.

\section{References}

1. Siegel RL, Miller KD, Jemal A. Cancer statistics, 2015. CA Cancer J Clin. 2015;65(1):5-29. doi:10.3322/caac.21254

2. Godavarty A, Rodriguez S, Jung YJ, Gonzalez S. Optical imaging for breast cancer prescreening. Breast Cancer (Dove Med Press). 2015;7:193-209. doi:10.2147/bctt.s51702

3. Gautherie M. Thermopathology of breast cancer: measurement and analysis of in vivo temperature and blood flow. Ann N Y Acad Sci. 1980;335:383-415.

4. Mehnati P, Tirtash MJ. Comparative Efficacy of Four Imaging Instruments for Breast Cancer Screening. Asian Pac J Cancer Prev. 2015;16(15):6177-6186.

5. Warner E, Plewes DB, Shumak RS, et al. Comparison of breast magnetic resonance imaging, mammography, and ultrasound for surveillance of women at high risk for hereditary breast cancer. J Clin Oncol. 2001;19(15):35243531. doi:10.1200/jco.2001.19.15.3524

6. Byrne C, Schairer C, Wolfe J, et al. Mammographic features and breast cancer risk: effects with time, age, and menopause status. J Natl Cancer Inst. 1995;87(21):16221629.

7. van Gils CH, Otten JD, Hendriks JH, Holland R, Straatman H, Verbeek AL. High mammographic breast density and its implications for the early detection of breast cancer. J Med Screen. 1999;6(4):200-204. doi:10.1136/jms.6.4.200

8. Simick MK, Jong R, Wilson B, Lilge L. Non-ionizing nearinfrared radiation transillumination spectroscopy for breast tissue density and assessment of breast cancer risk. J Biomed Opt. 2004;9(4):794-803. doi:10.1117/1.1758269

9. EtehadTavakol M, Sadri S, Ng EY. Application of K- and fuzzy c-means for color segmentation of thermal infrared breast images. J Med Syst. 2010;34(1):35-42.

10. Hall EJ, Giaccia AJ. Radiobiology for the Radiologist. Lippincott Williams \& Wilkins; 2006.

11. Wan S, Parrish JA, Anderson RR, Madden M. Transmittance of nonionizing radiation in human tissues. Photochem Photobiol. 1981;34(6):679-681.

12. Erfanzadeh M, Alikhani S, Ansari MA, Mohajerani E. A low-cost method for optical tomography. J Lasers Med Sci. 2011;3(3):102-108.

13. Afsari Golshan M, Ghasemi Tarei M, Ansari MA, Amjadi A. The Propagation of Laser Light in Skin by Monte Carlo-Diffusion Method: A Fast and Accurate Method to Simulate Photon Migration in Biological Tissues. J Lasers Med Sci. 2011;2(3):109-114.

14. Jacques SL. Optical properties of biological tissues: a review. Phys Med Biol. 2013;58(11):R37-61. doi:10.1088/00319155/58/11/r37

15. Venisnik KM, Olafsen T, Loening AM, Iyer M, Gambhir SS, Wu AM. Bifunctional antibody-Renilla luciferase fusion protein for in vivo optical detection of tumors. Protein Eng
Des Sel. 2006;19(10):453-460. doi:10.1093/protein/gzl030

16. Chen ZY, Wang YX, Lin Y, et al. Advance of molecular imaging technology and targeted imaging agent in imaging and therapy. BioMed Res Int. 2014;2014:12. doi:10.1155/2014/819324

17. Taber KH, Hillman EM, Hurley RA. Optical imaging: a new window to the adult brain. J Neuropsychiatry Clin Neurosci. 2010;22(4):iv, 357-360. doi:10.1176/appi. neuropsych.22.4.iv

18. Anderson PG, Kainerstorfer JM, Sassaroli A, et al. Broadband optical mammography: chromophore concentration and hemoglobin saturation contrast in breast cancer. PLoS One. 2015;10(3):e0117322. doi:10.1371/ journal.pone. 0117322

19. Leff DR, Warren OJ, Enfield LC, et al. Diffuse optical imaging of the healthy and diseased breast: a systematic review. Breast Cancer Res Treat. 2008;108(1):9-22. doi:10.1007/s10549-007-9582-z

20. van Veen RL, Sterenborg HJ, Marinelli AW, MenkePluymers M. Intraoperatively assessed optical properties of malignant and healthy breast tissue used to determine the optimum wavelength of contrast for optical mammography. J Biomed Opt. 2004;9(6):1129-1136. doi:10.1117/1.1803547

21. Etehadtavakol M, Lucas C, Sadri S, Ng EY. Analysis of breast thermography using fractal dimension to establish possible difference between malignant and benign patterns. J Healthc Eng. 2010;1(1):27-43.

22. Chance B, Nioka S, Zhang J, et al. Breast cancer detection based on incremental biochemical and physiological properties of breast cancers: a six-year, two-site study. Acad Radiol. 2005;12(8):925-933. doi:10.1016/j.acra.2005.04.016

23. Beaney RP, Lammertsma AA, Jones T, McKenzie CG, Halnan KE. Positron emission tomography for in-vivo measurement of regional blood flow, oxygen utilisation, and blood volume in patients with breast carcinoma. Lancet. 1984;1(8369):131-134.

24. Andres AC, Djonov V. The mammary gland vasculature revisited. J Mammary Gland Biol Neoplasia. 2010;15(3):319328. doi:10.1007/s10911-010-9186-9

25. Fantini S, Franceschini MA, Gaida G, et al. Frequencydomain optical mammography: edge effect corrections. Med Phys. 1996;23(1):149-157. doi:10.1118/1.597696

26. Gonzalez J, Roman M, Erickson SJ, Godavarty A. NearInfrared Hand-Held Optical Imaging Technology. J Indian Inst Sci. 2013;93(1):1-14.

27. Zhu Q, Cronin EB, Currier AA, et al. Benign versus malignant breast masses: optical differentiation with US-guided optical imaging reconstruction. Radiology. 2005;237(1):57-66. doi:10.1148/radiol.2371041236

28. Taroni P, Pifferi A, Torricelli A, Spinelli L, Danesini GM, Cubeddu R. Do shorter wavelengths improve contrast in optical mammography? Phys Med Biol. 2004;49(7):12031215.

29. Spinelli L, Torricelli A, Pifferi A, Taroni P, Danesini G, Cubeddu R. Characterization of female breast lesions from multi-wavelength time-resolved optical mammography. Phys Med Biol. 2005;50(11):2489-2502. doi:10.1088/0031$9155 / 50 / 11 / 004$

30. van de Ven S, Elias S, Wiethoff A, et al. Diffuse optical tomography of the breast: initial validation in benign cysts. Mol Imaging Biol. 2009;11(2):64-70. doi:10.1007/s11307- 
008-0176-x

31. Cerussi AE, Berger AJ, Bevilacqua F, et al. Sources of absorption and scattering contrast for near-infrared optical mammography. Acad Radiol. 2001;8(3):211-218. doi:10.1016/s1076-6332(03)80529-9

32. Mehnati P, Jafari Tirtash M, Zakerhamidi MS, Mehnati P. Assessing Absorption Coefficient of Hemoglobin in the Breast Phantom Using Near-Infrared Spectroscopy. Iran J Radiol. 2016;13(4):e31581. doi:10.5812/iranjradiol.31581

33. Ansari MA, Erfanzadeh M, Hosseini Z, Mohajerani E. Diffuse optical tomography: image reconstruction and verification. J Lasers Med Sci. 2014;5(1):13-18.

34. Busch DR, Guo W, Choe R, et al. Computer aided automatic detection of malignant lesions in diffuse optical mammography. Med Phys. 2010;37(4):1840-1849. doi:10.1118/1.3314075

35. Labib NA, Ghobashi MM, Moneer MM, Helal MH, Abdalgaleel SA. Evaluation of BreastLight as a tool for early detection of breast lesions among females attending National Cancer Institute, Cairo University. Asian Pac J Cancer Prev. 2013;14(8):4647-4650. 